OPEN ACCESS

Edited by:

Fiona Walsh

Maynooth University, Ireland

Reviewed by:

Atte Von Wright,

University of Eastern Finland, Finland

Asta Tvarijonaviciute,

Universitat Autònoma de Barcelona,

Spain

${ }^{*}$ Correspondence:

Ahmed M. Elazzazy

ahmedazazy8@hotmail.com

Specialty section:

This article was submitted to

Antimicrobials, Resistance and

Chemotherapy,

a section of the journal

Frontiers in Microbiology

Received: 20 February 2016

Accepted: 19 October 2016

Published: 10 November 2016

Citation:

Mahmoud WM, Abdelmoneim TS and

Elazzazy AM (2016) The Impact of

Silver Nanoparticles Produced by

Bacillus pumilus As Antimicrobial and

Nematicide. Front. Microbiol. 7:1746.

doi: 10.3389/fmicb.2016.01746

\section{The Impact of Silver Nanoparticles Produced by Bacillus pumilus As Antimicrobial and Nematicide}

\author{
Wael M. Mahmoud ', Tamer S. Abdelmoneim ${ }^{2,3}$ and Ahmed M. Elazzazy ${ }^{2,4 *}$ \\ ${ }^{1}$ Medical Genetics Department, Faculty of Medicine, University of Jeddah, Jeddah, Saudi Arabia, ${ }^{2}$ Biology Department, \\ Faculty of Science, University of Jeddah, Jeddah, Saudi Arabia, ${ }^{3}$ Department of Agricultural Botany, Faculty of Agriculture, \\ Suez Canal University, Ismailia, Egypt, ${ }^{4}$ Chemistry of Natural and Microbial Products Department, National Research Centre, \\ Giza, Egypt
}

This study evaluates the potential application of silver nanoparticles (AgNPs) as antimicrobial or nematicidal agents produced by the extremophile Bacillus pumilus, which was isolated from the alkaline Wadi El-Natrun Lake in Egypt. The AgNPs were characterized by ultraviolet-visible absorption spectroscopy, transmission electron microscopy, and energy dispersive x-ray spectroscopy. The size of AgNPs formed ranged from 20.12 to $29.48 \mathrm{~nm}$. Panagrellus redivivus was exposed to different concentrations $(0,50,100,150$, and $200 \mu \mathrm{g} / \mathrm{mL})$ of AgNPs in a $5 \mathrm{~mL}$ nematode suspension $\left(1 \times 10^{3} \mathrm{~mL}^{-1}\right)$. The best result occurred at AgNP concentrations of 150 and $200 \mu \mathrm{g} / \mathrm{mL}$, with death rates of 80 and $91 \%$, respectively, following $48 \mathrm{~h}$ of exposure. AgNPs also exhibited potent antimicrobial properties when using Gram-negative and Gram-positive human pathogens, with MIC and MBC values of 5 and $10 \mu \mathrm{g} / \mathrm{mL}$, respectively. These laboratory assays prove that biologically synthesized AgNPs are an ecofriendly material that can be used in lieu of solvents or toxic chemicals.

Keywords: silver, nanomaterials, bactericidal, nematicidal, ecofriendly materials

\section{INTRODUCTION}

Nanosilver, a therapeutically potent molecule, has captivated scientists from various disciplines (Galdiero et al., 2011). Diverse methods are currently being used for nanoparticle production, including physical, chemical, and hybrid systems (e.g., chemical reduction in aqueous or non-aqueous solutions (Petit et al., 1993), sonochemistry (Pol et al., 2002), microemulsions (Solanki and Murthy, 2010), and microwave-based systems Li et al., 2010). However, despite being both robust and technically feasible, many of these techniques involve perilous chemicals, are power intensive, and produce undesirable and/or wasteful byproducts (Kowshik et al., 2003; Mukunthan et al., 2011). Moreover, contamination of nanoparticles may have undesirable downstream effects, especially during therapeutic interventions (Jain et al., 2010). Therefore, there is a pressing need for harmless and effective nanoparticle production systems.

Over the last few years scientists have made significant progress in synthesizing ecofriendly and economically innocuous nanoparticles from different microorganisms (e.g., bacteria, actinomycetes; Ahmad et al., 2003; Sadowski et al., 2008; Sintubin et al., 2009). Biosynthesis of silver nanoparticles has been reported from bacteria, fungi, yeast, plants, and fruits (Jha et al., 2009). Gold and platinum nanoparticles have been widely utilized as novel antiviral, antimicrobial, anticancer, and anti-inflammatory agents (Hu et al., 2006; Jain et al., 2008). The potent antimicrobial 
characteristics of AgNPs have contributed to their use in a variety of medical and ecological applications, as well as in various consumer products (Kumar et al., 2008; Chaudhari et al., 2012).

Panagrellus redivivus is a free living nematode that plays an important role in decomposition, nutrient cycling, and ecosystem distribution in various microbial habitats (Félix and Braendle, 2010; Kim et al., 2012). Caenorhabditis elegans and $P$. redivivus are generally the preferred test nematodes in nanotoxicology (Kim et al., 2008, 2012; Roh et al., 2009; Wang et al., 2009). The toxicity of AgNPs toward nematodes has been previously studied in the gut and digestive organs of C. elegans (Meyer et al., 2010; Mohan et al., 2010). Here, we focused on the biosynthesis of AgNPs using the extracellular extract of a thermophilic strain, Bacillus pumilus, evaluating its use as an antimicrobial against various human pathogens and assessing the nematicidal effect toward $P$. redivivus. We also characterized the biosynthesized AgNPs using UVvisible spectroscopy, transmission electron microscopy, Fourier transform infrared spectroscopy, and energy dispersive X-ray spectroscopy.

\section{MATERIALS AND METHODS}

\section{Bacterial Strain and Sample Preparation}

The bacterial strain used in this study was isolated from the alkaline Wadi El-Natrun Lake in Egypt. The soil samples were collected in sterilized plastic bags and transferred to the laboratory. One gram of each soil sample was serially diluted, $100 \mu \mathrm{L}$ of each dilution was poured and spread onto nutrient agar plates, and the plates were incubated at $60 \pm 2{ }^{\circ} \mathrm{C}$ for 48 $\mathrm{h}$, distinct morphological colonies were picked and purified by serial streaking on nutrient agar (NA) plates. 16S rRNA gene sequencing was used to identify the bacterial species (Holt et al., 2000; Murray et al., 2005).

\section{Biomass Production}

The bacterial isolates were cultured in alkaline nutrient broth medium to produce biomass for silver biosynthesis. The culture flasks were incubated for $24 \mathrm{~h}$ and agitated on an orbital shaker at $220 \mathrm{rpm}$ at $\mathrm{pH} 10$ and $60^{\circ} \mathrm{C}$. The bacterial biomass was harvested by centrifugation at $5000 \mathrm{rpm}$ for $10 \mathrm{~min}$ after $24 \mathrm{~h}$ growth. The biomass was discarded and the supernatant material was collected for further processing.

\section{Synthesis of Silver Nanoparticles (AgNPs)}

$\mathrm{AgNO}_{3}(1 \mathrm{mM})$ was added to the culture supernatant and allowed to react for $24 \mathrm{~h}$; a control without silver ions was also run. All of the bacterial strains were screened for their ability to synthesize AgNPs by observing visible color changes and analyzing samples by UV-visible spectroscopy. Only the strains capable of AgNP synthesis were selected for further characterization of antimicrobial activity and by Fourier transform infrared spectroscopy, transmission electron microscopy, and energy dispersive X-ray spectroscopy.

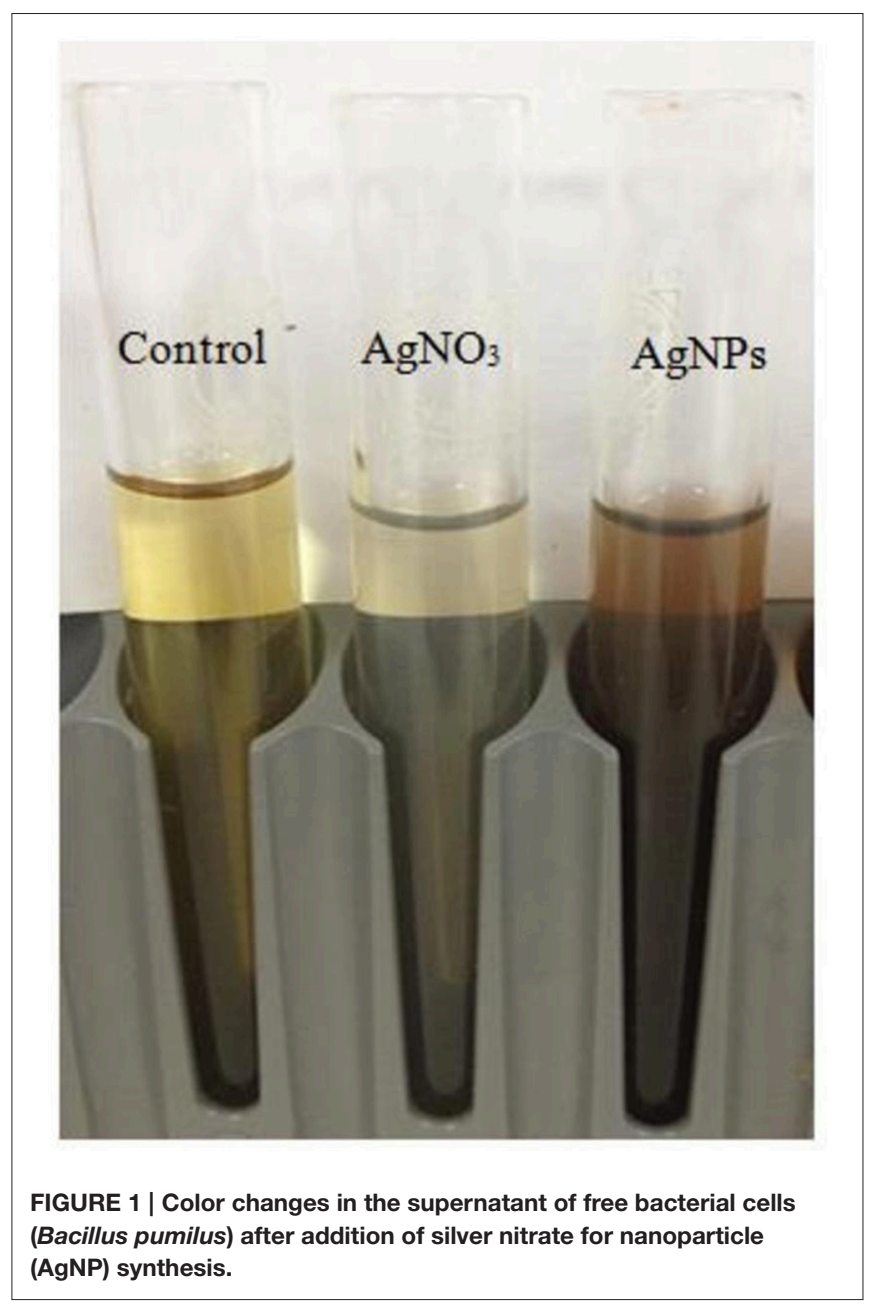

\section{Characterization of Silver Nanoparticles UV-Visible Spectroscopy}

Screening for AgNP synthesis was performed via visual observation of color conversion of the culture filtrate and UVvisible spectroscopy (Labomed-Korea; 200-1000 nm).

\section{Fourier Transform Infrared (FTIR)}

The FTIR spectrum of a dried sample was recorded on a Perkin Elmer instrument ranging from 450 to $4000 \mathrm{~cm}^{-1}$ at a resolution of $4 \mathrm{~cm}^{-1}$.

\section{Energy Dispersive X-Ray Spectroscopy (EDX)}

Elemental analysis was performed at $20 \mathrm{keV}$. A fine film of the sample was prepared on aluminum foil $(1 \times 1 \mathrm{~cm})$ by placing 100 $\mu \mathrm{L}$ of the supernatant onto the foil sheet and allowing it to dry for $30 \mathrm{~min}$.

\section{Transmission Electron Microscopy (TEM)}

Samples were prepared by removing the silver nanoparticles from the extract by centrifugation ( $5000 \mathrm{rpm}$ for $15 \mathrm{~min}$ ) and washing (twice) in sterile distilled water. A drop of the sample was applied to a carbon-coated copper grid. After about $1 \mathrm{~min}$, the excess 


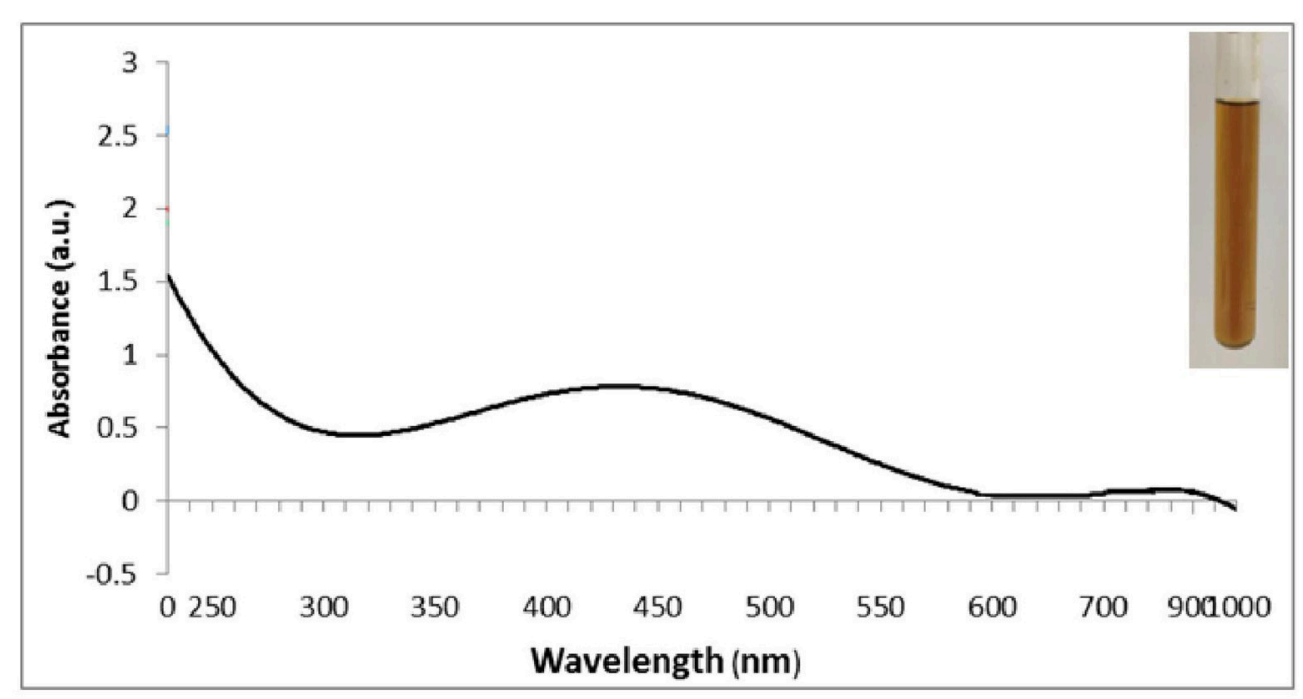

FIGURE 2 | UV-visible spectrum of silver nanoparticles (1 mM aqueous solution of $\mathbf{A g N O}_{3}$ ) synthesized by Bacillus pumilus. The inset of the figure shows a test tube of the silver nanoparticle solution formed at the end of the reaction.

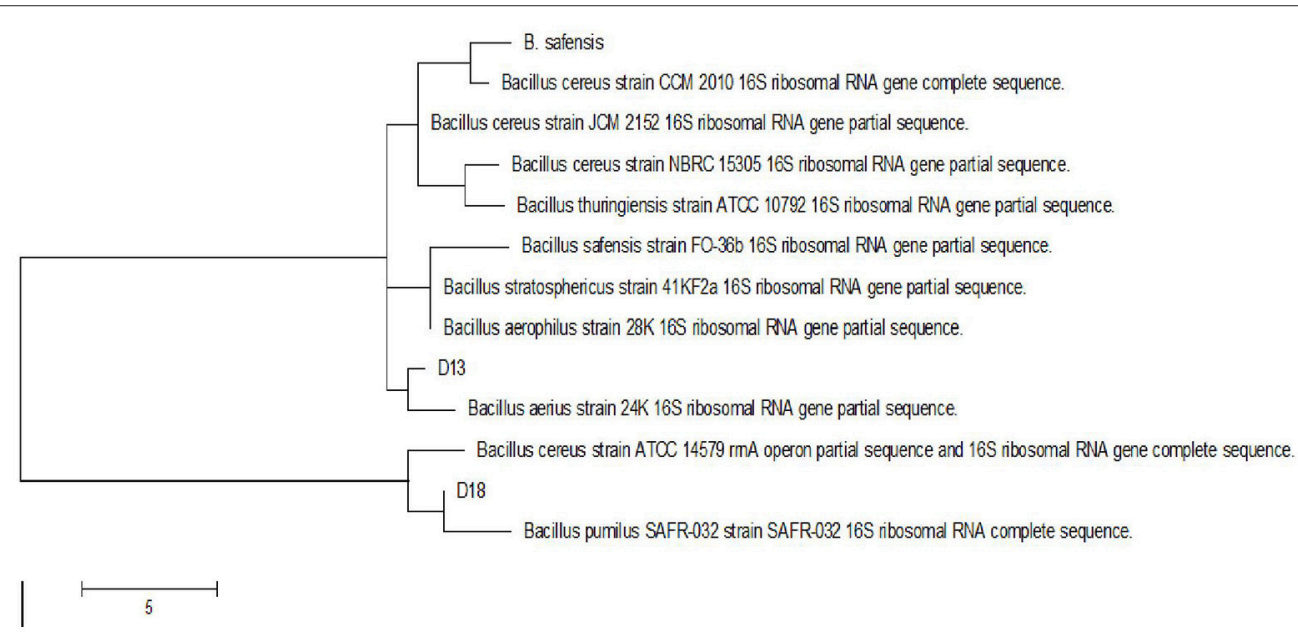

FIGURE 3 | Phylogenetic tree of Bacillus isolates (D18) based on partial 16S rRNA sequences.

solution was removed using blotting paper and the grid was air-dried before analysis.

\section{In-vitro Antibacterial Assay of Silver Nanoparticles by Agar-Well Diffusion Assay}

The well-diffusion technique was used to test the antimicrobial capabilities of the synthesized silver nanoparticles against multiple pathogenic strains, including: Methicillin-resistant Staphylococcus aureus [ATCC 43330 (MRSA)], Staphylococcus epidermidis [ATCC 12228 (S. epidermidis)], Streptococcus bovis [ATCC 49147 (S. bovis)], Escherichia coli [ATCC 25922 (E. coli)], Pseudomonas aeruginosa (clinical isolate), Shigella sonnei [ATCC 25931 (Sh. sonnei)], Klebsiella pneumoniae [ATCC 700603 (K. pneumoniae)], and Salmonella Typhimurium [ATCC 14028, (S. Typhimurium)]. Reaction mixtures $(50 \mu \mathrm{L})$ were loaded into each well and incubated overnight at $37 \pm 2{ }^{\circ} \mathrm{C}$. The sensitivity of the test organisms was determined by measuring the diameter of the inhibition zone around each well to the nearest colony $(\mathrm{mm})$.

\section{Determination of MIC and MBC}

The MIC was determined in Mueller Hinton broth using serial two-fold dilutions of AgNPs at concentrations ranging from 5 to $160 \mathrm{mg} / \mathrm{mL}$ with normalized bacterial concentrations $\left(1 \times 10^{8} \mathrm{CFU} / \mathrm{mL}, 0.5 \mathrm{McF}\right.$ arland's standard). The positive control contained $\mathrm{M}-\mathrm{H}$ broth with tested bacterial concentrations, and the negative control contained only inoculated broth. The samples were incubated for $24 \mathrm{~h}$ at $37^{\circ} \mathrm{C}$. The MIC is the minimum concentration of AgNPs that visually inhibits $99 \%$ of bacterial growth. The MBC 


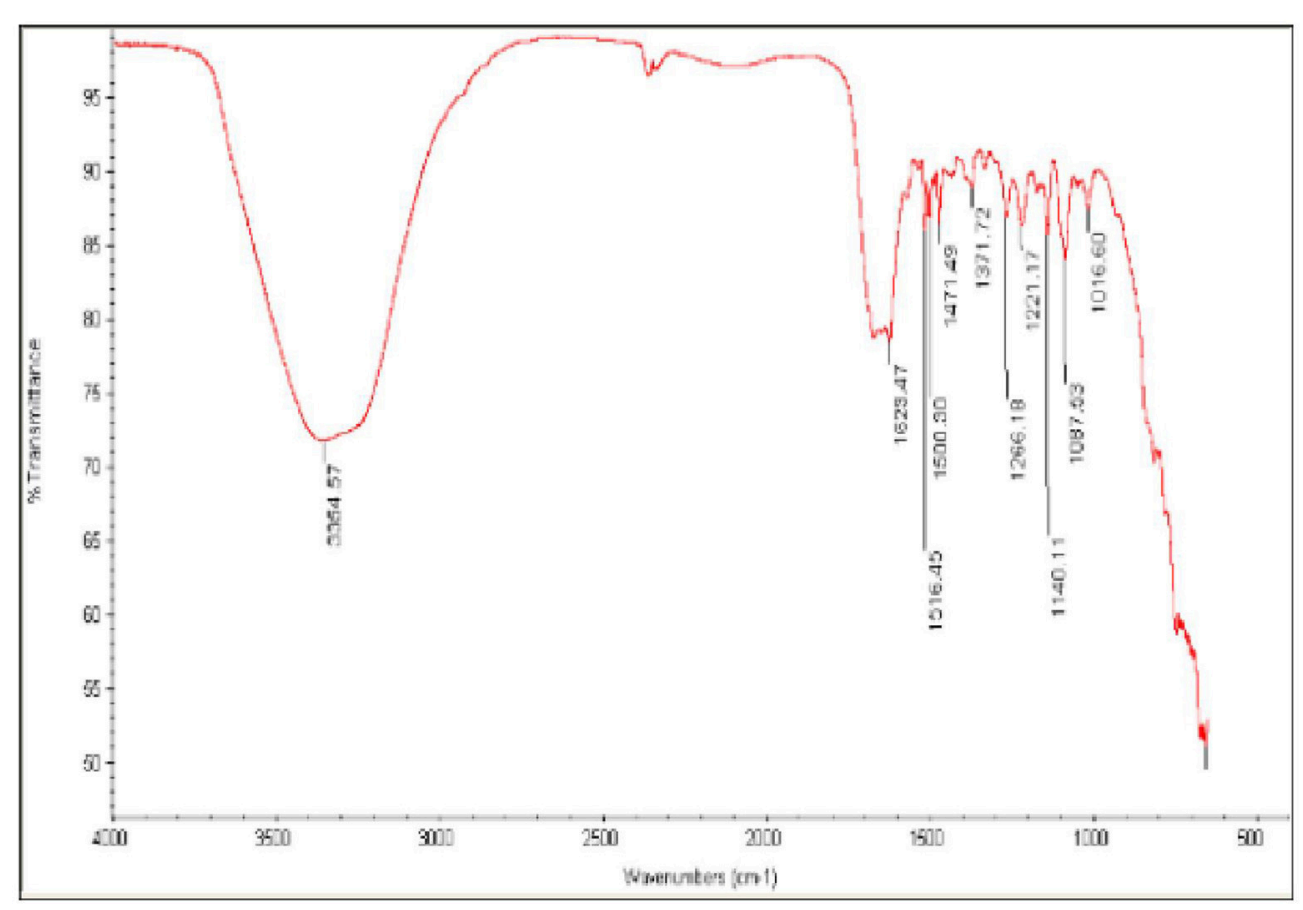

FIGURE 4 | Fourier-transform infrared (FT-IR) spectrum of silver nanoparticles synthesized by B. pumilus.

was determined by inoculating samples that did not show any growth of pathogenic bacteria on Müller-Hinton agar and observing growth after incubation at $37^{\circ} \mathrm{C}$ for $24 \mathrm{~h}$. The $\mathrm{MBC}$ is the minimum concentration yielding no growth.

\section{Toxicity Assay of AgNP Nematicidal Activity}

$P$. redivivus was obtained from the Nematology Lab in the Faculty of Agriculture at Suez Canal University (Ismailia, Egypt). The nematode cultures were maintained on nematode growth agar (peptone $2.5 \mathrm{~g} / \mathrm{L} ; 1 \mathrm{M}$ potassium phosphate 25 $\mathrm{mL} ; \mathrm{NaCl} 3 \mathrm{~g} / \mathrm{L} ; 1 \mathrm{M} \mathrm{MgSO} 4.7 \mathrm{H}_{2} \mathrm{O} 1 \mathrm{~mL} ; 1 \mathrm{M} \mathrm{CaCl}{ }_{2} .2 \mathrm{H}_{2} \mathrm{O}$ $1 \mathrm{~mL}$; cholesterol $1 \mathrm{~mL}$; agar $17 \mathrm{~g} / \mathrm{L}$ ) that was incubated at $21 \pm 2{ }^{\circ} \mathrm{C}$ in the dark for several weeks. E. coli was supplied as a food source. Juvenile nematodes were collected using a Clorox solution (1 M NaOH: $5 \% \mathrm{NaCl}, 5: 2)$. The solution was added to the nematode plate for $15 \mathrm{~min}$ and $1 \mathrm{~mL}$ of solution was added to $1.5 \mathrm{~mL}$ centrifuge tubes. The tubes were centrifuged for $2 \mathrm{~min}$ at $2000 \mathrm{rpm}$, and the supernatant was washed with K-medium (0.032 M KCl, 0.051 M NaCl; Williams and Dusenbery, 1990). The toxicity assay was carried out on nematode agar plates with AgNP suspensions. $P$. redivivus $\left(1 \times 10^{3} \mathrm{~mL}^{-1}\right)$ was exposed to $0,50,100,150$, or $200 \mu \mathrm{g} / \mathrm{mL}$ of AgNPs in a $5 \mathrm{~mL}$ nematode suspension to determine estimated mortality (\%) and survival number. Tests were performed in quadruplicate. The exposure periods for the assays were 24, 36, and $48 \mathrm{~h}$. The samples were analyzed using visual microscopy.

\section{Statistical Analysis}

Data were analyzed using ANOVA by using SAS statistical software (SAS Institute, Cary, NC, USA). When the main effect was significant $(P<0.05)$, differences between means were evaluated for significance by using Duncan's multiple-range test.

\section{RESULTS AND DISCUSSION}

The physical properties of biologically synthesized AgNPs may vary depending on the type of microorganism used for synthesis (Ahmad et al., 2003). In this study, about 20 bacterial isolates were screened for their ability to synthesize regularly-shaped silver nanoparticles. The 20 morphologically distinct bacterial isolates were grown on agar plates. The change of the cell-free filtrate from yellow to brown was the primary assay to determine whether the isolates that were capable of synthesizing AgNPs (Figure 1).

Following the addition of silver nitrate $(1 \mathrm{mM})$ to the filtrate of bacterial cultures, only the D18 isolate was able to change the color from yellowish to dark-brown, at $60^{\circ} \mathrm{C}$ within $2 \mathrm{~h}$ (Figure 1). The alteration in color is based on the surface plasmon resonance (SPR) of AgNPs. The control and blank tubes remained colorless (Chaudhari et al., 2012; Kirubha and Alagumuthu, 2013; Yamal et al., 2013). We validated AgNP synthesis using UV-visible spectrophotometry (Figure 2). This type of scanning has been useful in gauging SPR absorption of silver nanoparticles (Shahverdi et al., 2007; Ansari et al., 2011; Singh et al., 2011; Ponarulselvam et al., 2012). A strong SPR 
band was only observed at $430 \mathrm{~nm}$ for the D18 isolate. The UV-visible spectral bands observed at $430 \mathrm{~nm}$ are characteristic of silver nanoparticles (Figure 2; Petit et al., 1993; Ahmad et al., 2003; Singaravelu et al., 2007). Subsequently, the D18 isolate was identified as B. pumilus using $16 \mathrm{~S}$ rRNA sequencing (Figure 3).

Fourier transform infrared spectroscopy (FT-IR) measurements were used to determine if the biomolecules are susceptible to $\mathrm{Ag}^{+}$ion reduction and identify the capping agent of the bioreduced AgNPs (Figure 4). A band at 3500-3000 $\mathrm{cm}^{-1}$ in the FT-IR spectra is specific to the extending vibration of primary amines. The appearance of a band at about $1743 \mathrm{~cm}^{-1}$, which is assigned to extension of $\mathrm{C}=\mathrm{O}$ vibrations in carboxylic acids, aldehydes, and ketones, was notable and suggests the oxidation of the hydroxyl groups in bacterial hydrolysates coupled to the reduction of silver ions (Saha et al., 2010). The bands observed in the FT-IR spectra at $1650 \mathrm{~cm}^{-1}$ are an indicator of linkages of amide I and II (Sharma et al., 2012). The vibrations at $1500-1000 \mathrm{~cm}^{-1}$ may indicate methylene scissoring vibrations from the proteins in the bacterial filtrate (Sharma et al., 2012). The FT-IR spectra suggest that protein is the capping agent responsible for enclosing the bio-AgNPs (Vigneshwaran et al., 2007).
The morphology of the silver nanoparticles was analyzed using TEM (Figure 5A). The TEM images show mediated silver nano powder has triangular, hexagonal, spherical, pseudospherical, and some undefined morphology, with traces of agglomeration due to the binding of the biological molecules to the nanoparticles present in the bacteria (Malarkodi and Annadurai, 2013). The diameter of the nanoparticles ranged from 22.69 to $29.48 \mathrm{~nm}$.

We successfully used bacterial culture to synthesize small, relatively uniform, extracellular silver nanoparticles. Energydispersive spectroscopy was used to confirm the presence of elemental silver (Figure 5B), and silver nanocrystals were verified by an optical absorption band peak at $3 \mathrm{KeV}$, which is the same absorption as metallic silver nanocrystals based on SPR (Magudapathy et al., 2001). Other EDX signals emitted from O, $\mathrm{N}$, and $\mathrm{C}$ atoms were also observed. These peaks are probably due to X-ray emissions from the proteins and enzymes present in the cell free filtrates (Das et al., 2010). It is well-known that proteins can bind to nanoparticles either through free amino groups or through cysteine remnants in the protein (Mandal et al., 2005). Analysis of elemental composition via EDX showed the presence of silver atoms produced by $B$. pumilus; these results agree with the TEM results (Figures 5A,B).
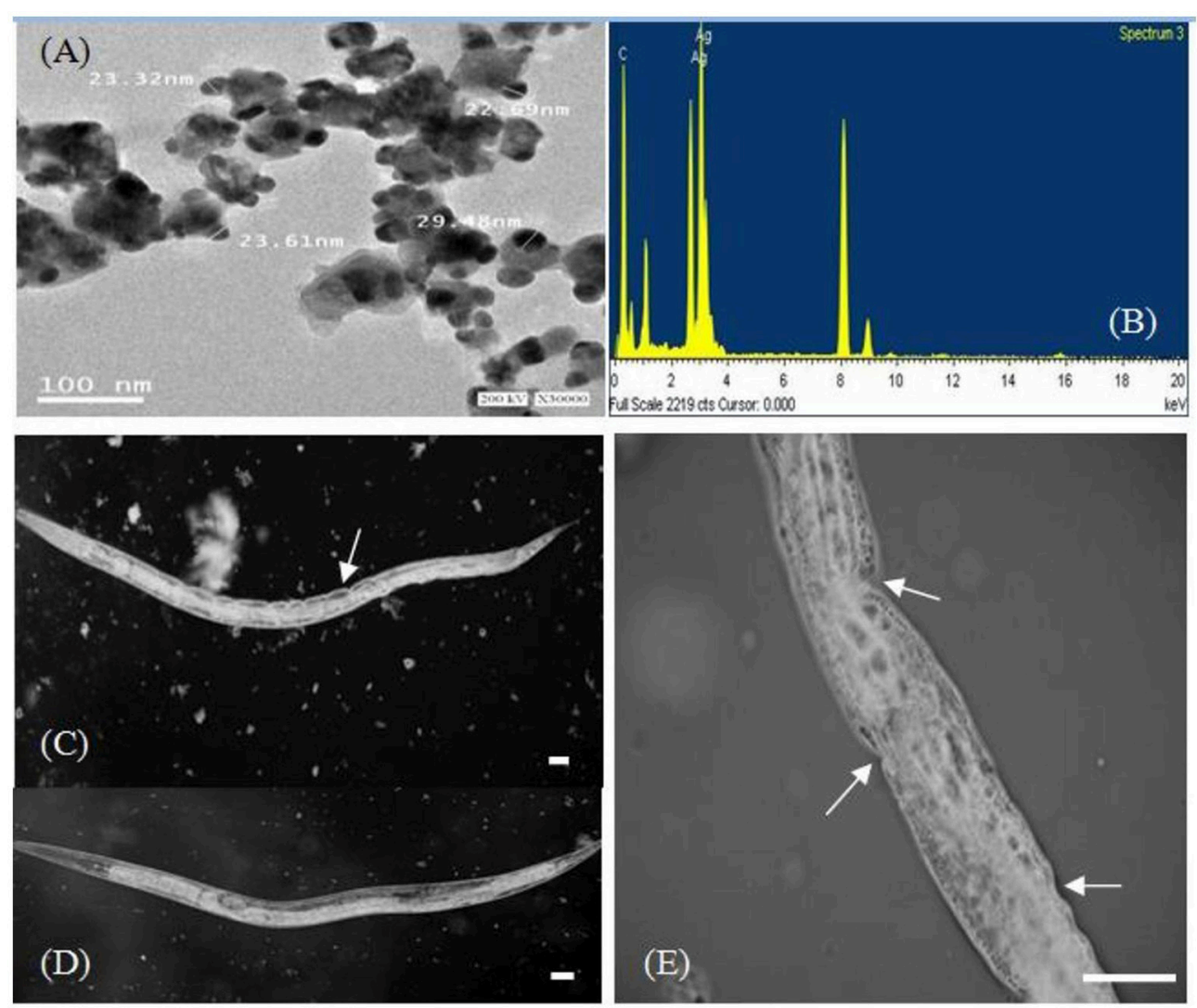

FIGURE 5 | TEM micrograph at 30,000x magnification (A) and energy-dispersive spectroscopy spectrum (B) of silver nanoparticles synthesized by B. pumilus. High-resolution microscopic images of the nematode $P$. redivivus $\mathbf{( C , E )}$ showing the epidermal malformation and necrosis (white arrows) resulting from AgNPs compared with controls (D; bar $=300 \mu \mathrm{m})$. 
The effects of AgNPs on a nematode cuticle ( $P$. redivivus) were observed using high-resolution microscopy. Figures 5C,E shows that the nematode cuticle "burst" when treated with AgNPs at 50, 100, 150, and $200 \mu \mathrm{g} / \mathrm{mL}$ after $48 \mathrm{~h}$ (Figures 5C,E); meanwhile, there was no effect on the control (Figure 5D). The same result was observed by Samberg et al. (2010), who found that AgNPs could penetrate animal skin and cause inflammation and edema at elevated levels, as well as epidermal hyperplasia at the highest concentration. Additionally, Wu et al. (2009) observed epidermal damage in various animal tissues subjected to AgNP treatment. Our results are in agreement with many previous studies (Vijver et al., 2003; Cunha et al., 2011; Kim et al., 2012).
The AgNPs formed by B. pumilus strain exhibited antibacterial activity against E. coli, S. bovis, K. pneumoniae, S. Typhimurium, $P$. aeruginosa, S. sonnei, and S. aureus (Figure 6). Shrivastava et al. (2007) suggested that Gram-positive bacteria are more sensitive to silver nanoparticles than Gram-negative bacteria because of the interactions of positively charged silver nanoparticles with negatively charged lipopolysaccharides. Yamanaka et al. (2005) reported antimicrobial effects of AgNPs on S. aureus and E. coli. The effect of AgNPs on bacterial strains may be due to the release of their ions inside the bacterial cell (Feng et al., 2000; Morones et al., 2005). The MIC and MBC of biosynthesized AgNPs for the majority of evaluated strains were in the range 5-20 $\mu \mathrm{g} / \mathrm{mL}$; meanwhile, for E. coli the MIC and

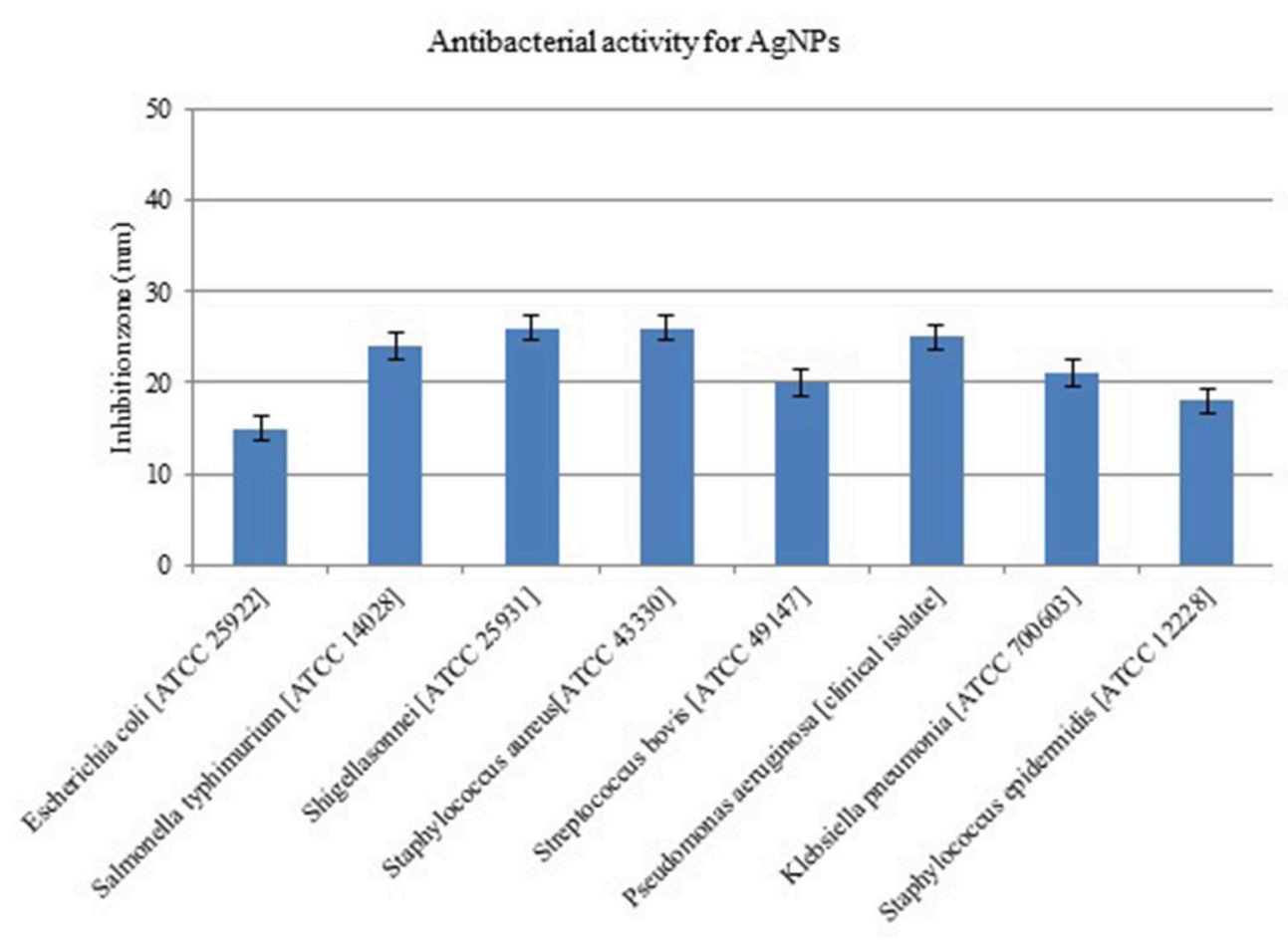

FIGURE 6 | Antimicrobial activity of silver nanoparticles (AgNPs) synthesized by B. pumilus against different pathogenic bacterial strains.

TABLE 1 | The mean of MIC and MBC values for silver nanoparticles (AgNPs) tested using human pathogens in M-H broth.

\begin{tabular}{|c|c|c|c|c|}
\hline Organism & \multicolumn{2}{|c|}{ AgNPs } & \multicolumn{2}{|c|}{ Tetracycline } \\
\hline Pseudomonas aeruginosa (clinical isolate) & $10 \pm 0.0$ & $20 \pm 3.6$ & $10 \pm 1.3$ & $20 \pm 1.0$ \\
\hline Salmonella Typhimurium ATCC 14028 & $10 \pm 0.58$ & $10 \pm 0.46$ & $10 \pm 0.0$ & $20 \pm 0.0$ \\
\hline Klebsiella pneumoniae ATCC 700603 & $10 \pm 0.0$ & $10 \pm 1.73$ & $5 \pm 0.0$ & $20 \pm 0.0$ \\
\hline Streptococcus bovis ATCC 49147 & $5 \pm 0.0$ & $10 \pm 0.1$ & $10 \pm 3.4$ & $20 \pm 0.0$ \\
\hline Staphylococcus epidermidis ATCC 12228 & $5 \pm 0.0$ & $10 \pm 0.5$ & $10 \pm 0.7$ & $10 \pm 0.0$ \\
\hline Staphylococcus aureus MRSA ATCC 43330 & $5 \pm 1.3$ & $20 \pm 1.0$ & $20 \pm 0.0$ & $<20 \pm 0.23$ \\
\hline
\end{tabular}

Determination of MICs and MBCS for AgNPs was performed at least three times in duplicate. MIC, Minimal inhibitory concentration; MBC, Minimal bactericidal concentration. 
TABLE 2 | The effect of different concentrations of silver nanoparticles (AgNPs, synthesized by B. pumilus) on $P$. redivivus after 24,36 , and $48 \mathrm{~h}$ of nematode growth.

\begin{tabular}{lccc}
\hline AgNPs $(\mu \mathbf{g} / \mathbf{m L})$ & \multicolumn{3}{c}{ Mortality (\%) } \\
\cline { 2 - 4 } & $\mathbf{2 4 h}$ & $\mathbf{3 6 h}$ & $\mathbf{4 8 ~ h}$ \\
\hline Untreated & $0.50^{\mathrm{d}}$ & $0.500^{\mathrm{d}}$ & $0.63^{\mathrm{c}}$ \\
50 & $55.0^{\mathrm{c}}$ & $58.00^{\mathrm{c}}$ & $60.0^{\mathrm{b}}$ \\
100 & $63.0^{\mathrm{b}}$ & $65.00^{\mathrm{b}}$ & $65.33^{\mathrm{b}}$ \\
150 & $89.0^{\mathrm{a}}$ & $89.67^{\mathrm{a}}$ & $91.0^{\mathrm{a}}$ \\
200 & $84.0^{\mathrm{a}}$ & $85.17^{\mathrm{a}}$ & $88.0^{\mathrm{a}}$ \\
\end{tabular}

Means in each column followed by the same letter are not significantly different $(P<0.05)$ as determined by Duncan's multiple range test.

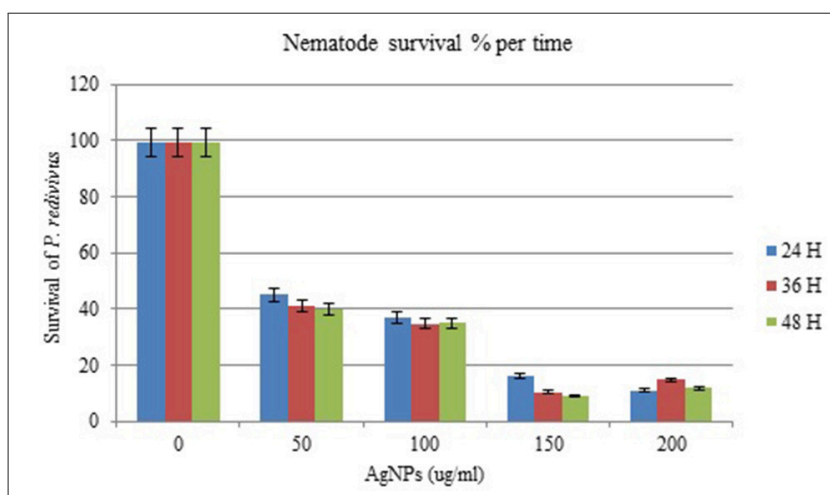

FIGURE 7 | The effect of different concentrations of silver nanoparticles (AgNPs) synthesized by B. pumilus on $P$. redivivus survival (\%) after 24,36 , and $48 \mathrm{~h}$ incubation in nematode growth medium.

MBC were $\sim 40$ and $80 \mu \mathrm{g} / \mathrm{mL}$, respectively (Table 1 ). The three Gram-positive pathogens had MIC values of $5 \mu \mathrm{g} / \mathrm{mL}$; however, the MIC for the Gram-negative strains was $10 \mu \mathrm{g} / \mathrm{mL}$. The MBC did not exceed $20 \mu \mathrm{g} / \mathrm{mL}$ for any strain. Our results show better antibacterial activity than those of Ansari et al. (2011), Ayala-Núñez et al. (2009), and Fernández et al. (2008), who reported MIC and MBC values ranging from 12.5 to $25 \mu \mathrm{g} / \mathrm{mL}$. This was likely due to the smaller size of the nanoparticles in our study. Li et al. (2011) showed complete inhibition of the growth of $S$. aureus ATCC $6538 \mathrm{P}$ at $20 \mu \mathrm{g} / \mathrm{mL}$. The mechanism(s) of AgNP antimicrobial activity may differ depending on the bacterial species and the nanoparticle size (Ansari et al., 2011).

The effect of AgNPs on the survival and mortality (shown as $\%$ per time) of $P$. redivivus was significant at 50,100, 150,

\section{REFERENCES}

Ahmad, A., Mukherjee, P., Senapati, S., Mandal, D., Khan, M. I., Kumar, R., et al. (2003). Extracellular biosynthesis of silver nanoparticles using the fungus Fusarium oxysporum. Colloids Surf. B Biointerfaces 28, 313-318. doi: 10.1016/S0927-7765(02)00174-1

Ansari, M. A., Khan, H. M., Khan, A. A., Malik, A., Sultan, A., Shahid, M., et al. (2011). Evaluation of antibacterial activity of silver nanoparticles and $200 \mu \mathrm{g} / \mathrm{mL}$ compared to untreated nematodes (Table 2). Moreover, increased exposure time was proportional to mortality (\%) for all except the two highest concentrations (150 and $200 \mu \mathrm{g} / \mathrm{mL}$ ). This was likely due to the aggregation of AgNPs at these high concentrations. This result agrees with those of Kim et al. (2012), Baek and An (2011), and Lee et al. (2011), who all found that the aggregation of nanoparticles at high concentrations inhibited nanoparticle toxicity. In addition, nematode survivability increased significantly with decreased exposure time (Figure 7). We believe that increasing exposure time may increase the chances of nematode feeding, interactions with AgNPs, and toxicity. This is supported by Meyer et al. (2010), who confirmed the presence of AgNPs in the nematode gut and unlaid eggs. Furthermore, Chithrani and Chan (2007) reported that the cellular uptake of nanoparticles is controlled by the wrapping time of binding sites on the cell surface.

\section{CONCLUSIONS}

Bionanotechnology contributes to the development of therapeutic interventions for many conditions, including cancer, bacterial infections, and viruses. Biosynthesis of nanoparticles eliminates many problems associated with chemical synthesis. Biosynthesized nanoparticles can be used in minimal amounts to inhibit pathogen and nematode growth without any harmful side-effects, thus replacing conventional antibiotics and chemical nematicides. Nanoparticle production is ecofriendly, does not require any solvents or toxic chemicals, and is easily scalable. We have shown that AgNPs can be used as potent antibacterial agents against various pathogenic microorganisms.

\section{AUTHOR CONTRIBUTIONS}

WM, TA, and AE conceived and designed the experiments; AE carried out the antimicrobial activities studies; TA performed the nematicidal experiments; TA and AE analyzed the data; WM, TA, and $\mathrm{AE}$ wrote the paper. All authors have read and approved the final manuscript.

\section{ACKNOWLEDGMENTS}

This project was funded by the Deanship of Scientific Research (DSR), University of Jeddah, Jeddah, under grant No. G-1436965-574. The authors, therefore, acknowledge and thank DSR for technical and financial support.

against MSSA and MSRA on isolates from skin infections. Biol. Med. 3, 141-146.

Ayala-Núñez, N. V., Lara Villegas, H. H., del Carmen Ixtepan Turrent, L., and Padilla, C. R. (2009). Silver nanoparticles toxicity and bactericidal effect against Methicillin-resistant Staphylococcus aureus: nanoscale does matter. Nanobiotechnology 5, 2-9. doi: 10.1007/s12030-009-9029-1

Baek, Y. W., and An, Y. J. (2011). Microbial toxicity of metal oxide nanoparticles $\left(\mathrm{CuO}, \mathrm{NiO}, \mathrm{ZnO}\right.$, and $\left.\mathrm{Sb}_{2} \mathrm{O}_{3}\right)$ to Escherichia coli, Bacillus 
subtilis, and Streptococcus aureus. Sci. Total Environ. 409, 1603-1608. doi: 10.1016/j.scitotenv.2011.01.014

Chaudhari, P. R., Masurkar, S. A., Shidore, V. B., and Kamble, S. P. (2012). Antimicrobial activity of extracellularly synthesized silver nanoparticles using Lactobacillus species obtained from VIZYLAC capsule. J. Appl. Pharm. Sci. 2, 25-29.

Chithrani, B. D., and Chan, W. C. (2007). Elucidating the mechanism of cellular uptake and removal of protein-coated gold nanoparticles of different sizes and shapes. Nano Lett. 7, 1542-1550. doi: 10.1021/nl070363y

Cunha, L., Campos, I., Montiel, R., Rodrigues, A., and Morgan, A. J. (2011). Morphometry of the epidermis of an invasive megascoelecid earthworm (Amynthas gracilis, Kinberg 1867) inhabiting actively volcanic soils in the Azores archipelago. Ecotoxicol. Environ. Saf. 74, 25-32. doi: 10.1016/j.ecoenv. 2010.08.004

Das, S. K., Das, A. R., and Guha, A. K. (2010). Microbial synthesis of multishaped gold nanostructures. Small 6, 1012-1021. doi: 10.1002/smll.200902011

Félix, M. A., and Braendle, C. (2010). The natural history of Caenorhabditis elegans. Curr. Biol. 20, R965-R969. doi: 10.1016/j.cub.2010.09.050

Feng, Q. L., Wu, J., Chen, G. Q., Cui, F. Z., Kim, T. N., and Kim, J. O. (2000). A mechanistic study of the antibacterial effect of silver ions on Escherichia coli and Staphylococcus aureus. J. Biomed. Mater. Res. 52, 662-668.

Fernández, E. J., García-Barrasa, J., Laguna, A., López-de Luzuriaga, J. M., Monge, M., and Torres, C. (2008). The preparation of highly active antimicrobial silver nanoparticles by an organometallic approach. Nanotechnology 19, 1-6. doi: 10.1088/0957-4484/19/18/185602

Galdiero, S., Falanga, A., Vitiello, M., Cantisani, M., Marra, V., and Galdiero, M. (2011). Silver nanoparticles as potential antiviral agents. Molecules 16, 8894-8918. doi: 10.3390/molecules16108894

Holt, J. G., Krieg, R. N., Sneath, P. H. A., Staley, J. T., and Williams, S. T. (2000). Bergey's Manual of Determinative Bacteriology, 9th Edn., ed W. R. Hensyl (Baltimore, MD: William and Willkins), 559-562.

Hu, M., Chen, J., Li, Z. Y., Au, L., Hartland, G. V., Li, X., et al. (2006). Gold nanostructures: engineering their plasmonic properties for biomedical applications. Chem. Soc. Rev. 35, 1084-1094. doi: 10.1039/b517615h

Jain, D., Kachhwaha, S., Jain, R., Srivastava, G., and Kothari, S. L. (2010). Novel microbial route to synthesize sliver nanoparticles using spore crystal mixture of Bacillus thuringiensis. Indian J. Exp. Biol. 48, 1152-1156.

Jain, P. K., Huang, X., El-Sayed, I. H., and El-Sayed, M. A. (2008). Noble metals on the nanoscale: optical and photothermal properties and some applications in imaging, sensing, biology, and medicine. Acc. Chem. Res. 41, 1578-1586. doi: 10.1021/ar7002804

Jha, A. K., Prasad, K., Kumar, V., and Prasad, K. (2009). Biosynthesis of silver nanoparticles using Eclipta leaf. Biotechnol Prog. 25, 1476-1479. doi: 10.1002/btpr.233

Kim, J., Takahashi, M., Shimizu, T., Shirasawa, T., Kajita, M., Kanayama, A., et al. (2008). Effects of a potent antioxidant, platinum nanoparticle, on the lifespan of Caenorhabditis elegans. Mech. Ageing Dev. 129, 322-331. doi: 10.1016/j.mad. 2008.02.011

Kim, S. W., Nam, S. H., and An, Y. J. (2012). Interaction of silver nanoparticles with biological surfaces of Caenorhabditis elegans. Ecotoxicol. Environ. Saf. 77, 64-70. doi: 10.1016/j.ecoenv.2011.10.023

Kirubha, R., and Alagumuthu, G. (2013). Morindatinctoria fruit assisted biosynthesis of silver nanoparticles. Asian J. Pharm. Clin. Res. 6, 60-64.

Kowshik, M., Ashtaputre, S., Kharrazi, S., Vogel, W., Urban, J., Kulkarni, S. K., et al. (2003). Extracellular synthesis of silver nanoparticles by a silver-tolerant yeast strain MKY3. Nanotechnology 14, 95-100. doi: 10.1088/0957-4484/14/1/321

Kumar, A., Vemula, P. K., Ajayan, P. M., and John, G. (2008). Silver-nanoparticleembedded antimicrobial paints based on vegetable oil. Nat. Mater. 7, 236-241. doi: 10.1038/nmat2099

Lee, W. M., Ha, S. W., Yang, C. Y., Lee, J. K., and An, Y. J. (2011). Effect of fluorescent silica nanoparticles in embryo and larva of Oryzias latipes: sonic effect in nanoparticle dispersion. Chemosphere 82, 451-459. doi: 10.1016/ j.chemosphere.2010.09.055

Li, W.-R, Xie, X.-B, Shi, Q.-S., Duan, S.-S., Ouyang, Y.-S., and Chen, Y.-B. (2011). Antibacterial effect of silver nanoparticles on Staphylococcus aureus. Biometals. 24, 135-141. doi: 10.1007/s10534-010-9381-6

Li, X., Wang, L., and Lu, X. (2010). Preparation of silver-modified TiO2 via microwave-assisted method and its photocatalytic activity for toluene degradation. J. Hazard. Mater. 177, 639-647. doi: 10.1016/j.jhazmat 2009.12.080

Magudapathy, P., Gangopadhyay, P., Panigrahi, B. K., Nair, K. G. M., and Dhara, S. (2001). Electrical transport studies of Ag nanocrystallites embedded in glass matrix. Physica B 299, 142-146. doi: 10.1016/S0921-4526(00)00580-9

Malarkodi, C., and Annadurai, G. (2013). A novel biological approach on extracellular synthesis, and characterization of semiconductor zinc sulfide nanoparticles. Appl. Nanosci. 3, 389-395. doi: 10.1007/s13204-012-0138-0

Mandal, S., Phadtare, S., and Murali, S. (2005). Interfacing biology with nanoparticles. Curr. Appl. Phys. 5, 118-127. doi: 10.1016/j.cap.2004.06.006

Meyer, J. N., Lord, C. A., Yang, X. Y., Turner, E. A., Badireddy, A. R., Marinakos, S. M., et al. (2010). Intracellular uptake and associated toxicity of silver nanoparticles in Caenorhabditis elegans. Aquat. Toxicol. 100, 140-150. doi: 10.1016/j.aquatox.2010.07.016

Mohan, N., Chen, C. S., Hsieh, H. H., Wu, Y. C., and Chang, H. C. (2010). In vivo imaging and toxicity assessments of fluorescent nanodiamonds in Caenorhabditis elegans. Nano Lett. 10, 3692-3699. doi: 10.1021/nl1021909

Morones, J. R., Elechiguerra, J. L., Camacho, A., Holt, K., Kouri, J. B., Ramírez, J. T., et al. (2005). The bactericidal effect of silver nanoparticles. Nanotechnology 16, 2346-2353. doi: 10.1088/0957-4484/16/10/059

Mukunthan, K. S., Elumalai, E. K., Patel, T. N., and Murty, V. R. (2011). Catharanthus roseus: a natural source for the synthesis of silver nanoparticles. Asian Pac. J. Trop. Biomed. 1, 270-274. doi: 10.1016/S2221-1691(11)60041-5

Murray, P. R., Baron, E. J., Pfaller, M. A., Tenover, F. C., and Yolker, R. H. (2005). Manual of Clinical Microbiology, eds N. A. Logan, P. C. B. Turnbull (Washington, DC: American Society for Microbiology), 357-365.

Petit, C., Lixon, P., and Pileni, M. P. (1993). In situ synthesis of silver nanocluster in AOT reverse micelles. J. Phys. Chem. 97, 12974-12983.

Pol, V. G., Srivastava, D. N., Palchik, O., Palchik, V., Slifkin, M. A., Weiss, A. M. et al. (2002). Sonochemical deposition of silver nanoparticles on silica spheres. Langmuir. 18, 3352-3357. doi: 10.1021/la0155552

Ponarulselvam, S., Panneerselvam, C., Murugan, K., Aarthi, N., Kalimuthu, K., and Thangamani, S. (2012). Synthesis of silver nanoparticles using leaves of Catharan thusroseus Linn. G. Don and their antiplasmodial activities. Asian Pac. J. Trop. Biomed. 2, 574-580. doi: 10.1016/S2221-1691(12)60100-2

Roh, J. Y., Sim, S. J., Yi, J., Park, K., Chung, K. H., Ryu, D. Y., et al. (2009). Ecotoxicity of silver nanoparticles on the soil nematode Caenorhabditis elegans using functional ecotoxicogenomics. Environ. Sci. Technol. 43, 3933-3940. doi: $10.1021 / \mathrm{es} 803477 \mathrm{u}$

Sadowski, Z., Maliszewska, I., Polowczyk, I., Kozlecki, T., and Grochowalska, B. (2008). Biosynthesis of colloidal-silver particles using microorganisms. Polish J. Chem. 82, 377-382.

Saha, S., Sarkar, J., Chattopadhayay, D., Patra, S., Chakraborty, A., and Acharya, K. (2010). Production of silver nanoparticles by a phytopathogenic fungus bipolarisnodulosa and its antimicrobial activity. Dig. J. Nanomater. Biostruct. $5,887-885$

Samberg, M. E., Oldenburg, S. J., and Monteiro-Riviere, N. A. (2010). Evaluation of silver nanoparticle toxicity in skin in vivo and keratinocytes in vitro. Environ. Health Perspect. 118, 407-413. doi: 10.1289/ehp.0901398

Shahverdi, A. R., Fakhimi, A., Shahverdi, S. R., and Minaian, S. (2007). Synthesis and effect of silver nanoparticles on the antibacterial activity of different antibiotics against Staphylococcus aureus and Escherichia coli. Nanomedicine 3, 168-171. doi: 10.1016/j.nano.2007.02.001

Sharma, N., Pinnaka, A. K., Raje, M., Fnu, A., Bhattacharyya, M. S., and Choudhury, A. R. (2012). Exploitation of marine bacteria for production of gold nanoparticles. Microb. Cell Fact. 11:86. doi: 10.1186/1475-2859-11-86

Shrivastava, S., Bera, T., Roy, A., Singh, G., Ramachandrarao, P., and Dash, D. (2007). Characterization of enhanced antibacterial effects of novel silver nanoparticles. Nanotechnology 18, 1-9. doi: 10.1088/0957-4484/18/22/ 225103

Singaravelu, G., Arockiamary, J. S., Ganesh Kumar, V., and Govindaraju, K. (2007). A novel extracellular synthesis of monodisperse gold nanoparticles using marine alga, Sargassum wightii Greville. Colloids Surf B Biointerfaces 57, 97-101. doi: 10.1016/j.colsurfb.2007.01.010

Singh, P., Kumar, R., Balaji, R., and Kalaichelvan, P. T. (2011). Mycobased biosynthesis of silver nanoparticles and studies of its synergistic antibacterial activity combined with cefazolin antibiotic against selected organisms. Aust. J. Basic Appl. Sci. 5, 1412-1427. 
Sintubin, L., De Windt, W., Dick, J., Mast, J., Van der Ha, D., Verstraete, W., et al. (2009). Lactic acid bacteria as reducing and capping agent for the fast and efficient production of silver nanoparticles. Appl. Microbiol. Biotechnol. 84, 741-749. doi: 10.1007/s00253-009-2032-6

Solanki, J. N., and Murthy, Z. V. P. (2010). Highly monodisperse and sub-nano silver particles synthesis via microemulsion technique. Colloids Surf. A. 359, 31-38. doi: 10.1016/j.colsurfa.2010.01.058

Vigneshwaran, N., Ashtaputre, N. M., Varadarajan, P. V., Nachane, R. P., Paralikar, K. M., and Balasubramanya, R. H. (2007). Biological synthesis of silver nanoparticles using the fungus Aspergillus flavus. Mat. Lett. 61, 1413-1418. doi: 10.1016/j.matlet.2006.07.042

Vijver, M. G., Vink, J. P., Miermans, C. J., and van Gestel, C. A. (2003). Oral sealing using glue: a new method to distinguish between intestinal and dermal uptake of metals in earthworms. Soil Biol. Biochem. 35, 125-132. doi: 10.1016/S00380717(02)00245-6

Wang, H., Wick, R. L., and Xing, B. (2009). Toxicity of nanoparticulate and bulk $\mathrm{ZnO}, \mathrm{Al}_{2} \mathrm{O}_{3}$ and $\mathrm{TiO}_{2}$ to the nematode Caenorhabditis elegans. Environ. Pollut. 157, 1171-1177. doi: 10.1016/j.envpol.2008.11.004

Williams, P. L., and Dusenbery, D. B. (1990). Aquatic toxicology testing using the nematode Caenorhabditis elegans. Environ. Toxicol. Chem. 9, 1285-1290. doi: $10.1002 /$ etc. 5620091007
Wu, J., Liu, W., Xue, C., Zhou, S., Lan, F., Bi, L., et al. (2009). Toxicity and penetration of $\mathrm{TiO} 2$ nanoparticles in hairless mice and porcine skin after subchronic dermal exposure. Toxicol. Lett. 191, 1-8. doi: 10.1016/j.toxlet. 2009.05.020

Yamal, G., Sharmila, P., Rao, K. S., and Pardha-Saradhi, P. (2013). Inbuilt potential of YEM medium and its constituents to generate $\mathrm{Ag} / \mathrm{Ag}_{2} \mathrm{O}$ nanoparticles. PLoS ONE 8:e61750. doi: 10.1371/journal.pone. 0061750

Yamanaka, M., Hura, K., and Kudo, J. (2005). Study of antibacterial activity. Appl. Environ. Microbiol. 71, 7589-7593.

Conflict of Interest Statement: The authors declare that the research was conducted in the absence of any commercial or financial relationships that could be construed as a potential conflict of interest.

Copyright (๑) 2016 Mahmoud, Abdelmoneim and Elazzazy. This is an open-access article distributed under the terms of the Creative Commons Attribution License (CC $B Y)$. The use, distribution or reproduction in other forums is permitted, provided the original author(s) or licensor are credited and that the original publication in this journal is cited, in accordance with accepted academic practice. No use, distribution or reproduction is permitted which does not comply with these terms. 